\title{
Characteristics of two-component epoxy modified bitumen
}

\author{
Y. Xiao • M. F. C. van de Ven • \\ A. A. A. Molenaar $\cdot$ Z. Su $\cdot$ F. Zandvoort
}

Received: 8 April 2010/Accepted: 26 July 2010/Published online: 5 August 2010

(C) The Author(s) 2010. This article is published with open access at Springerlink.com

\begin{abstract}
Coal tar bearing emulsions were used in the Netherlands as binder in anti-skid surfaces for runways because of their perfect adhesion and fuel resistance properties. They are however toxic and will not be allowed anymore after 2010. Therefore alternatives need to be developed. As one of the alternatives, two types of two-component epoxy modified bitumen have been investigated by means of direct tensile tests (DTT), relaxation tests (RT) and dynamic shear rheometer (DSR) tests. The effect of the curing temperature on the strength development of the epoxy modified bitumen was tested. The results show that the tensile strength increases with increasing curing time and temperature. DTT and RT results indicate that this new epoxy modified bitumen has a much higher tensile strength, cures faster than a bitumen emulsion as a binder. Furthermore, it shows
\end{abstract}

Y. Xiao $(\bowtie) \cdot$ M. F. C. van de Ven · A. A. A. Molenaar Faculty of Civil Engineering \& Geosciences, Delft University of Technology, Delft, The Netherlands e-mail:Yue.Xiao@tudelft.nl

M. F. C. van de Ven

e-mail: m.f.c.vandeven@tudelft.nl

A. A. A. Molenaar

e-mail: A.A.A.Molenaar@tudelft.nl

Z. Su $\cdot$ F. Zandvoort

Icopal BV, Groningen, The Netherlands

e-mail: nlzsu@icopal.com

F. Zandvoort

e-mail: nlfza@icopal.com a good stress relaxation even at lower temperatures. The curing speed and the ultimate tensile strength after full curing can be easily adjusted. The DSR results show that the complex modulus of this epoxy modified binder is less susceptible to changes in temperature. The results also suggest that this epoxy modified bitumen has better anti-crack properties at lower temperature and less permanent deformation than bituminous binders at higher temperatures. All these results shows that this type of two-component epoxy modified bitumen can be promising as a binder in anti-skid layers.

Keywords Epoxy modified bitumen · Curing property - Direct tensile test - Relaxation test . Dynamic shear rheometer test

\section{Introduction}

Until now, coal tar bearing emulsions were widely used as binders for anti-skid surfaces for runways in the Netherlands because of their perfect adhesion and excellent fuel resistance. Unfortunately, coal tar is toxic and carcinogenic due to its high Polycyclic Aromatic Hydrocarbons content. Therefore it will not be allowed on runways anymore after 2010 [17].

Bitumen emulsions, which can be stored and applied at low temperatures, seem to be the right material for replacing coal tar as binder in antiskid surfaces for runways [3]. Ooms and CITGO 
companies [12, 14] developed several types of modified bitumen which have a good fuel resistance. But these materials do not have comparable properties like coal tar anti-skid. Van Leest [17] reported about the evaluation of types of existing surface treatment products. He concluded that none of the selected surface treatment layers could achieve the same performance for all properties as the tar bearing anti-skid functioned.

Mixtures with epoxy modified bitumen are different compared with conventional bitumen mixtures. They neither become brittle at low temperature nor melt at high temperatures [4]. Epoxy bitumen is a flexible material that can be cold-applied in thin surface layers. When used on roads, it sets quickly enough to allow early traffic even before full curing, which enables the roadway to be reopened within $2 \mathrm{~h}$ $[1,5]$. Epoxy bitumen is reported to be extremely durable as well as flexible. Surfaces with epoxy bitumen obtained maximum skid resistance and produce less noise. Epoxy bitumen has excellent adhesion properties, high resistance to surface abrasion from tyre action and is sufficiently resistant to the action of fuel spillage from jet-type aircraft $[2,4,6]$.

In order to find possible alternatives for tar bearing anti-skid, a new kind of two-component cold mixing epoxy modified bitumen was developed and evaluated in this paper.

\section{Material}

The two-component epoxy modified bitumen was obtained from ICOPAL Company. Two types were investigated, namely Esha Seal 2C-I and Esha Seal $2 \mathrm{C}$-II. The difference between the two types is the chemical composition and mechanical properties.

The epoxy components were carefully selected, showing excellent compatibility with bitumen without phase separation and proper mechanical properties. The hardening mechanism is based on a chemical reaction between component $\mathrm{A}$ and $\mathrm{B}$ after mixing, leading to an open 3-dimensional structure of epoxy resin throughout a bitumen based matrix. Therefore, the mixture shows the advantages of both epoxy and bitumen. Component A is bitumen based. It is a special mix of bitumen, additives, fillers and different bitumen-compatible epoxides.
The physical properties of both types of materials are given in Tables 1 and 2.

\section{Sample preparation and test methods}

The sample preparation steps were as the following steps. After this preparation process, samples were cured in certain temperature cabinet for different curing time. Then direct tensile tests (DTT) ${ }^{1}$, relaxation tests (RT) and dynamic shear rheometer (DSR) tests were used for properties investigation.

(1) Add component B to component A with a right volume ratio as Tables 1 and 2 show at room temperature.

(2) Mix thoroughly with a mixing machine till a homogeneous mix is obtained (1-2 min). Homogeneous mixing of components $\mathrm{A}$ and $\mathrm{B}$ is necessary for making the samples for DTT and DSR tests.

(3) Then prepare the samples by pouring the mixture into a mould for DTT and/or DSR test specimens. Air voids need to be avoided.

\subsection{Direct tensile test}

Figure 1 indicates the size of the DTT samples, and Fig. 2(1) shows typical DTT samples in the mould. During this procedure, over filling is needed to ensure that enough binder is available to completely fill the mould. Sample preparation is critical and has large influence on the test variation $[10,13,15]$.

The moulded DTT samples were stored at different temperatures conditions to determine the influence of curing temperatures and curing time on the development.

Normally, the DTT test for bitumen binder/mortar is using samples as shown in Fig. 2(1). But for this two component material, the tensile strength is much stronger than the adhesion strength between the binder and steel. It always breaks at the adhesion zone between the binder and steel, instead of through the binder. In order to avoid this undesirable adhesion

\footnotetext{
${ }^{1}$ http://www.pavementinteractive.org/index.php?title=Direct_ Tension_Tester.
} 
Table 1 Technical information of Esha Seal 2C-I

Table 2 Technical information of Esha Seal 2C-II

Fig. 1 The size of DTT samples

Fig. 2 Sample preparations for DTT test

\begin{tabular}{llll}
\hline Properties & Value (typical) & & Method \\
\cline { 2 - 3 } & Component A & Component B & \\
\hline Appearance & Viscose liquid & Viscose liquid & \\
Colour & Black & Yellowish & \\
Viscosity Pa s at $25^{\circ} \mathrm{C}$ & $18 \pm 5$ & $0,40 \pm 0.10$ & EN 13302 \\
Density g/ml & $1.4 \pm 0.1$ & $1.0 \pm 0.1$ & \\
Volume ratio for mixing & 4.91 & 1 & \\
\hline
\end{tabular}

\begin{tabular}{llll}
\hline Properties & Value (typical) & & Method \\
\cline { 2 - 3 } & Component A & Component B & \\
\hline Appearance & Viscose liquid & Viscose liquid & \\
Colour & Black & Yellowish & EN 13302 \\
Viscosity Pa s at $25^{\circ} \mathrm{C}$ & $3 \pm 0.5$ & $0.40 \pm 0.10$ & \\
Density g/ml & $1.4 \pm 0.1$ & $1.0 \pm 0.1$ & \\
Volume ratio for mixing & 5.00 & 1 & \\
\hline
\end{tabular}
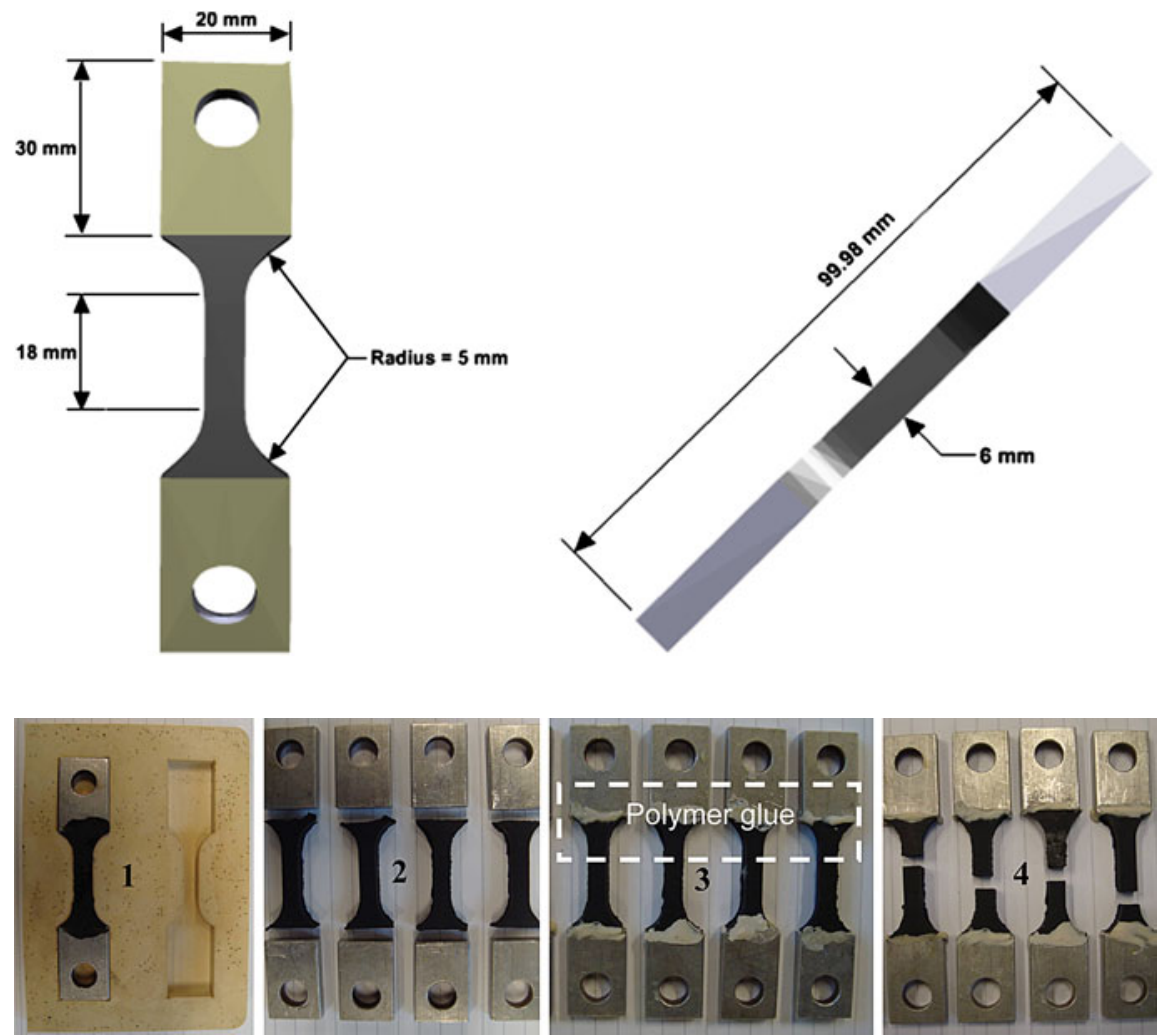

failure, samples were stored in the fridge at $-5^{\circ} \mathrm{C}$ for half an hour and then the samples were broken by hand at the interfaces between binder and steel. After that the samples were glued to the steel again using a polymer glue. This is shown in Fig. 2(3). Figure 2(4) shows the specimens after the tensile test.

After a certain period of curing time (see Table 3), the samples were tested at a constant tensile rate until 
Table 3 Curing temperature and time for different tests

\begin{tabular}{|c|c|c|c|}
\hline $\begin{array}{l}\text { Test } \\
\text { type }\end{array}$ & Material & $\begin{array}{l}\text { Curing } \\
\text { temperature }\left({ }^{\circ} \mathrm{C}\right)\end{array}$ & Curing time (day) \\
\hline \multirow[t]{6}{*}{ DTT } & \multirow{3}{*}{$\begin{array}{l}\text { Esha Seal } \\
2 \mathrm{C}-\mathrm{I}\end{array}$} & 15 & $1,2,3,4 \& 7$ \\
\hline & & 20 & $1,2,34 \& 7$ \\
\hline & & 30 & $1,2 \& 3$ \\
\hline & \multirow{3}{*}{$\begin{array}{l}\text { Esha Seal } \\
2 \mathrm{C}-\mathrm{II}\end{array}$} & 15 & $2,3,4,5,6,9 \& 11$ \\
\hline & & 20 & $2,3,4,8,9 \& 11$ \\
\hline & & 30 & $\begin{array}{l}2,4,5,7,8,10,12,13 \\
\quad 14 \& 15\end{array}$ \\
\hline \multirow[t]{2}{*}{$\mathrm{RT}$} & $\begin{array}{l}\text { Esha Seal } \\
\text { 2C-I }\end{array}$ & 25 & 7 \\
\hline & $\begin{array}{l}\text { Esha Seal } \\
2 \mathrm{C} \text {-II }\end{array}$ & 30 & 15 \\
\hline \multirow[t]{2}{*}{ DSR } & $\begin{array}{l}\text { Esha Seal } \\
2 \mathrm{C}-\mathrm{I}\end{array}$ & 20 & 7 \\
\hline & $\begin{array}{l}\text { Esha Seal } \\
2 \mathrm{C}-\mathrm{II}\end{array}$ & & 15 \\
\hline
\end{tabular}

they failed. The failure stress and displacement are recorded. The following equations are used to calculate the failure stress and strain.

Failure stress : $\sigma_{\mathrm{f}}=\frac{\mathrm{P}_{\mathrm{f}}}{\mathrm{A}}$

where, $\sigma_{\mathrm{f}}$ is failure stress, $(\mathrm{MPa})$; $\mathrm{A}$ is original crosssectional area, $\left(\mathrm{mm}^{2}\right)$, here $\mathrm{A}=36 \mathrm{~mm}^{2} ; \mathrm{P}_{\mathrm{f}}$ is failure load, (N).

The effective length to calculate the strain:

Strain $: \varepsilon=\frac{\mathrm{D}}{\mathrm{L}_{\mathrm{e}}}$

where, $\varepsilon$ is strain; $\mathrm{D}$ is the displacement, $(\mathrm{mm}) ; \mathrm{L}_{\mathrm{e}}$ is the effective length of DTT samples, $(\mathrm{mm})$. If the entire sample length $(40 \mathrm{~mm})$ is used for the strain calculations, the actual strain occurring in the center section $(18 \mathrm{~mm})$ is underestimated. However, it is not possible to establish reliable reference points for the laser system to measure the displacement only in the central part $(18 \mathrm{~mm})$. Therefore, an effective length of $33.8 \mathrm{~mm}$ is used as the equivalent length since it results in a close approximation of the actual strain in the central of $18 \mathrm{~mm}$ section $(18 \mathrm{~mm})$.

The top graph in Fig. 3 shows the loading force and displacement against loading time as measured during a Direct Tensile test. The maximum loading force of the tester used in this research is $600 \mathrm{~N}$. Therefore, some of the tensile tests stopped automatically because they were out of range.
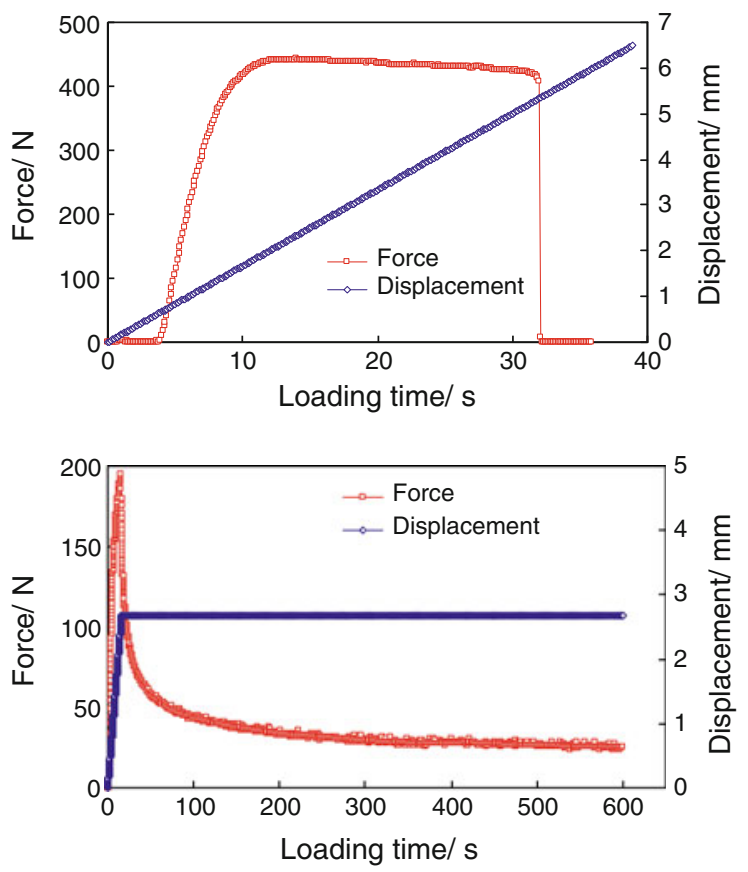

Fig. 3 Typical loading displacement and applied force curves for DTT (top) and RT (bottom)

\subsection{Relaxation test}

The RT samples were similar to the DTT samples. The RT was conducted at a constant temperature. Relaxation time and loading force are monitored at the considered testing temperatures. The test is performed in three steps. First, the specimens are conditioned in the testing machine at the specified test temperature for 60-75 $\mathrm{min}$. Then a constant displacement rate of $10 \mathrm{~mm} / \mathrm{min}$ is applied till a load of approximately $200 \mathrm{~N}$ is reached. Afterwards, the displacement is fixed constant and the relaxation of stress is monitored.

The relaxation percentage at certain time can be calculated using the following equation:

$\mathrm{R}=\left(1-\frac{\mathrm{F}_{\text {Remain }}}{\mathrm{F}_{\text {Applied }}}\right) \times 100$

where, $\mathrm{R}$ is relaxation percentage, (\%); $\mathrm{F}_{\mathrm{Remain}}$ is remaining force after relaxation at certain time, $(\mathrm{N})$; $\mathrm{F}_{\text {Applied }}$ is the maximum applied force, $(\mathrm{N})$.

The bottom graph in Fig. 3 shows a typical graph of the loading and displacement curves against time for a relaxation test. 


\subsection{Dynamic shear rheometer test}

The DSR is used to characterize the viscous and elastic behavior of the binder at different frequencies and temperatures ranging from low to high. The complex shear modulus $\left(G^{*}\right)$ and phase angle $(\delta)$ are evaluated with a frequency sweep using a sinusoidal signal. The complex shear modulus can be considered as the sample's total resistance to deformation during the sinusoidal shear load, while the phase angle is the lag between the applied sinusoidal shear stress and the resulting shear strain. The larger the phase angle, the more viscous the material, and the higher the $G^{*}$ value, the stiffer the binder is.

Frequency sweeps are used to evaluate the phase angle and complex modulus of these two-component binders. The selected test temperatures were $-10,0$, $10,20,40$ and $60^{\circ} \mathrm{C}$. The size of the specimens for the DSR test was as show in Fig. 4 [7, 8]. The frequency sweep result of pen grade bitumen was used for comparison.

The curing regime of temperature is shown in Table 3. All of these DSR specimens were stored in a climate cabinet at the temperature of $20^{\circ} \mathrm{C}$. The curing time is based on the test results from DTT to make sure the specimens were fully cured.

Table 3 shows the curing process for different tests with certain curing times and temperatures.

\section{Test results and discussion}

In this section the effects of curing regime on the DTT, RT and DSR properties are presented and discussed. First the effects of curing conditions on the DTT properties is investigated and discussed. After that, the curing regime (curing time and curing temperature) for the other tests is determined based on DDT results.

\subsection{Direct tensile test results}

DTT tests were used to evaluate the sensitivity of the binders to curing time and curing temperature. The influence of test temperature and displacement rate on the DTT results was determined.

\subsubsection{Curing time and temperature sensitivity}

The influence of curing temperature was investigated by curing at three temperatures, e.g. 15,20 and $30^{\circ} \mathrm{C}$. The influence of the curing time was investigated by changing the curing time (see Table 3 ).

Tables 4 and 5 and Figs. 5 and 6 show the DTT test results. The test was terminated automatically when the applied force reached the maximum level that could be generated by the DTT device. Two specimens with the same curing regime were tested as parallel tests. The DTT test was conducted at a temperature of $20^{\circ} \mathrm{C}$, with a displacement rate of $10 \mathrm{~mm} / \mathrm{min}$.

Tables 4 and 5 show that the direct tensile strength increases with curing time. The higher the curing temperatures, the fast the direct tensile strength developed. Materials at $30^{\circ} \mathrm{C}$ show the highest curing rate. For Esha Seal 2C-I, the tensile strength after 2 days curing at $30^{\circ} \mathrm{C}$ was out of range, while it took 5 days to reach a similar strength level at $10^{\circ} \mathrm{C}$.

The test results of Esha Seal 2C-II data were fitted by means of a sigmoidal curve, while the data of $2 \mathrm{C}-\mathrm{I}$ is not enough because of the fast strength development. The sigmoidal curve function is shown below:

$\mathrm{S}_{\mathrm{T}}=\delta+\alpha /\left(1+\mathrm{e}^{\beta-\gamma \times \mathrm{t}_{\text {curing }}}\right)$

where, $\alpha, \beta, \gamma$ and $\delta$ are sigmoidal function coefficients (fitting parameters); $S_{\mathrm{T}}$ is the tensile strength and $t_{\text {curing }}$ is the curing time $[16,11]$.
Fig. 4 Binders for DSR test

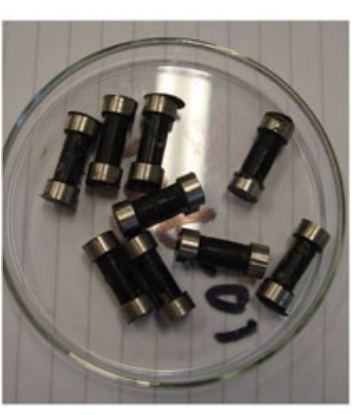

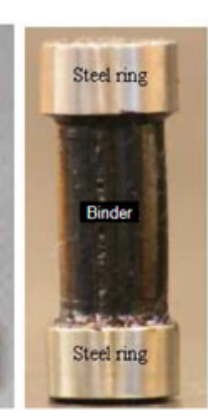

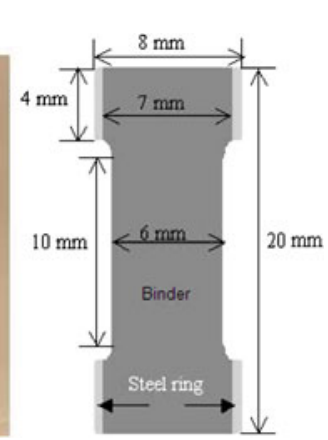

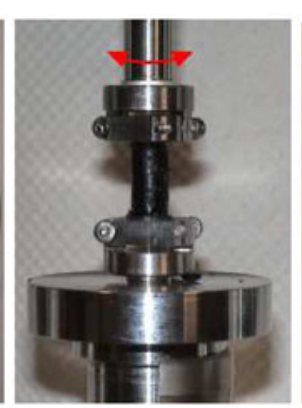

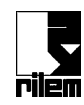


Table 4 Influence of curing time and temperatures on direct tensile strength (MPa) of Esha Seal 2C-I

\begin{tabular}{clllll}
\hline Tensile strength & \multicolumn{5}{l}{ Day } \\
\cline { 2 - 6 } & 1 & 2 & 3 & 4 & 7 \\
\hline Curing temperature $\left({ }^{\circ} \mathrm{C}\right)$ & & & & \\
15 & 4.82 & 7.55 & 9.43 & 12.81 & $>17$ \\
20 & 5.42 & 10.06 & 13.91 & $>17$ & $>17$ \\
30 & 11.32 & $>17$ & $>17$ & - & - \\
\hline
\end{tabular}

Table 5 Influence of curing time and temperatures on direct tensile strength of Esha Seal 2C-II

\begin{tabular}{llll}
\hline Curing time (day) & \multicolumn{4}{l}{ Curing temperature $\left({ }^{\circ} \mathrm{C}\right)$} \\
\cline { 2 - 4 } & 15 & 20 & 30 \\
\hline 2 & 2.20 & 3.56 & 3.75 \\
3 & 3.84 & 4.41 & - \\
4 & 4.39 & 4.59 & 4.31 \\
5 & 4.39 & - & 4.48 \\
6 & 4.68 & - & - \\
7 & - & - & 4.96 \\
8 & - & 4.75 & 4.98 \\
9 & 4.92 & 4.93 & - \\
10 & - & - & 5.12 \\
11 & 5.09 & 5.37 & - \\
12 & - & - & 5.21 \\
13 & - & - & 5.17 \\
14 & - & - & 5.48 \\
15 & - & - & 5.60 \\
\hline
\end{tabular}

The parameters of the sigmoidal curves for Esha Seal 2C-II are shown in Table 6. In general, these curves fit the data very well. After 10 days, the tensile strength still keeps increasing. The sigmoidal curve functions show that after 10 days the tensile strength for Esha Seal $2 \mathrm{C}$-II is around $5 \mathrm{MPa}$. The actual data however show a slight increase in strength after 10 days curing. This could be on one hand due to the further trace of chemical reaction between component $\mathrm{A}$ and $\mathrm{B}$, on the other hand due to the aging influence by conditioning the sample in the oven for such a long period of time.

By comparing Esha Seal 2C-I and 2C-II, it can be concluded that the tensile strength and curing rate can be easily adjusted by changing the additive content.

Tables 4 and 5 show that the tensile strength of Esha Seal 2C-I is $4.82 \mathrm{MPa}$ after 1 day curing at $15^{\circ} \mathrm{C}$, whereas for Esha Seal $2 \mathrm{C}$-II, it will be only $2.20 \mathrm{MPa}$ cured at the same temperature for 2 days. This indicates that the hardening process and ultimate properties of the epoxy modified bitumen can be easily adjusted, depending on its composition and the amount of additives. The binder gains rapidly enough tensile strength allowing the runway to be reopened for planes even before they get full cured.

\subsubsection{Loading speed and test temperature sensitivity}

The influence of the test temperature on the DTT results was only determined on Esha Seal 2C-I. All the test samples were cured for 7 days at $25^{\circ} \mathrm{C}$ (ambient temperature), which were supposed to have fully cured based on the DTT results and Fig. 5.

Tests were performed at 10,20 and $25^{\circ} \mathrm{C}$, with a displacement rate of $1 \mathrm{~mm} / \mathrm{min}$. The influence of the displacement rate sensitivity was evaluated at $20^{\circ} \mathrm{C}$ with rates of 1,10 and $100 \mathrm{~mm} / \mathrm{min}$, respectively. The results are shown in Table 7 and Fig. 7.

The results show that the tensile strength of this two-component epoxy modified bitumen is depending on the loading speed and test temperature. The failure stress increases with decreasing test temperatures and increasing loading speed.

\subsection{Relaxation test results}

For the relaxation tests, a constant loading speed was applied based to the direct tensile test results. In this case, the load was induced with a displacement rate of $10 \mathrm{~mm} / \mathrm{min}$ until the stress on the specimen was around $30-50 \%$ of the ultimate tensile strength in order to avoid damage to the specimen.

All relaxation tests were carried out after full curing. Table 1 shows the curing procedures for the specimens. Samples of Esha Seal 2C-I were cured at $25^{\circ} \mathrm{C}$ for 7 days, and samples of Esha Seal 2C-II were cured at $30^{\circ} \mathrm{C}$ for 15 days. The test results are shown in Table 8 and Figs. 8 and 9.

The results show that these two-component binders still have some relaxation properties even at lower temperature $\left(-10^{\circ} \mathrm{C}\right)$. At $-10^{\circ} \mathrm{C}$ the stress relaxation is more than $20 \%$, and for Esha Seal 2C-II, the stress relaxation is almost $30.5 \%$. These reasonable relaxation properties give good low temperature performance. At higher temperatures $\left(20^{\circ} \mathrm{C}\right)$, both binders have stress relaxation percentage above $90 \%$. 
Fig. 5 Influence of curing time and temperatures on direct tensile strength of Esha Seal 2C-I

Fig. 6 Influence of curing time and temperatures on direct tensile strength of Esha Seal 2C-II
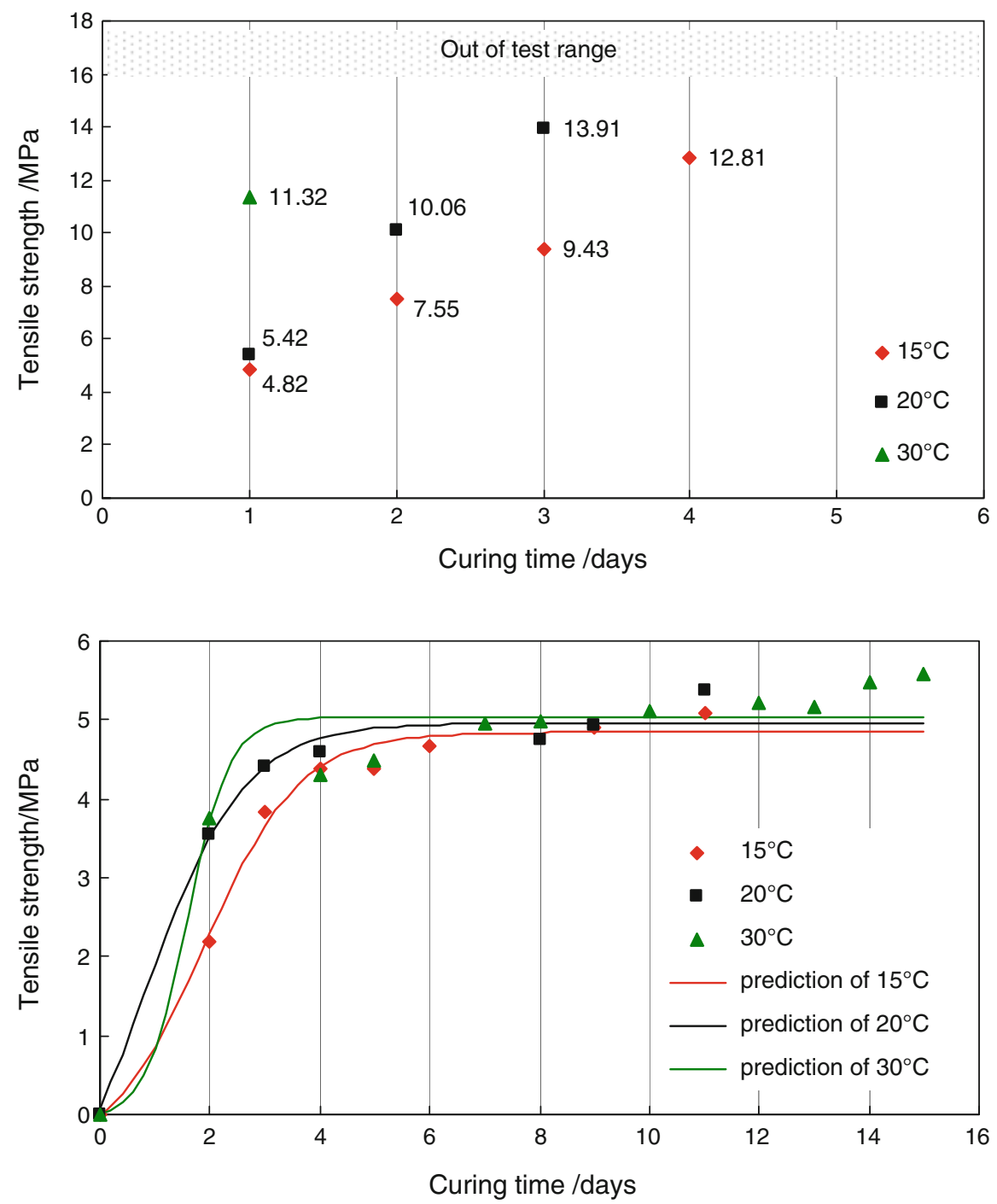

Table 6 Parameters of the sigmoidal curves for Esha Seal 2C-II

\begin{tabular}{lllllll}
\hline Binder & Curing temperature $\left({ }^{\circ} \mathrm{C}\right)$ & $\delta$ & $\alpha$ & $\beta$ & $\gamma$ & $\mathrm{R}^{2}$ \\
\hline Esha Seal 2C-II & 15 & -0.56852 & 5.41168 & 2.17142 & 1.14568 \\
& 20 & -1.97494 & 6.935937 & 0.863631962 & 1.0975 \\
& 30 & -0.07502 & 5.11017 & 4.15340 & 2.61560 & 0.9879 \\
& & & 0.9438 \\
\hline
\end{tabular}

\subsection{DSR test results}

The complex modulus and phase angle as obtained from the DSR tests are shown in Figs. 10 and 11, respectively. Figure 10 shows that the complex modulus of Esha Seal 2C-II is lower than the Esha Seal 2C-I modulus at the same temperature and same frequency. Figure 11 shows that the phase angle of Esha Seal 2C-I is higher than that of 2C-II at lower temperatures and/or higher frequency. This indicates that the elastic and viscous part of this two component product can be easily changed by varying the content of the additives. 
Table 7 Test results for Esha Seal 2C-I at different test temperature and loading speed

\begin{tabular}{llll}
\hline Test temperature $\left({ }^{\circ} \mathrm{C}\right)$ & Displacement loading rate & Maximum force/N & Failure stress/MPa \\
\hline 25 & $1 \mathrm{~mm} / \mathrm{min}$ & 219.44 & 6.096 \\
20 & & 342.37 & 9.510 \\
10 & & $>600$ & $>17$ \\
20 & $10 \mathrm{~mm} / \mathrm{min}$ & 473.06 & 13.141 \\
& $100 \mathrm{~mm} / \mathrm{min}$ & $>600$ & $>17$ \\
\hline
\end{tabular}

Fig. 7 Test results obtained at different test temperatures and displacement rates

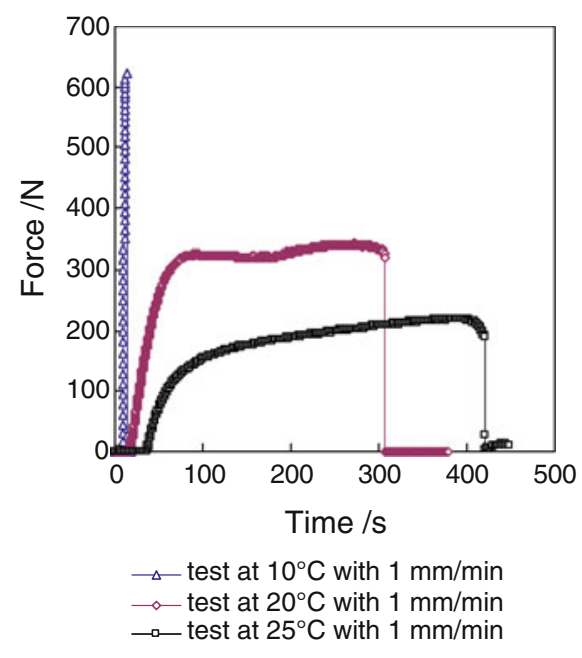

The phase angle and complex modulus at $10 \mathrm{~Hz}$ are shown in Table 9. The results reveal that Esha Seal 2C-II is of more viscous characteristic than Esha Seal 2C-I viscous because of its lower complex modulus and a higher phase angle.

The test results are used to build-up the master curves of complex modulus and phase angle for each binder. The master curves were constructed by using the Williams-Landel-Ferry (WLF) theory which is as follows [9]:

Table 8 Results of relaxation tests $\log \mathrm{a}_{\mathrm{t}}=\frac{\mathrm{C}_{1}\left(\mathrm{~T}-\mathrm{T}_{\mathrm{ref}}\right)}{\mathrm{C}_{2}+\left(\mathrm{T}-\mathrm{T}_{\mathrm{ref}}\right)}$

where $a_{t}$ is the shift factor value, $C_{1}$ and $C_{2}$ are constants, $\mathrm{T}$ is measurement temperature and $\mathrm{T}_{\text {ref }}$ is reference temperature $\left(20^{\circ} \mathrm{C}\right)$.

The master curves for Esha Seal 2C-I and 2C-II are shown in Fig. 12, compared with the master curves for pen grade bitumen (AH 90) as shown in Table 10. The reference temperature is $20^{\circ} \mathrm{C}$. The

\begin{tabular}{lrlcl}
\hline & Temp. $\left({ }^{\circ} \mathrm{C}\right)$ & $\mathrm{F}_{\text {Applied }} / \mathrm{N}$ & $\mathrm{F}_{\text {Remain }} / \mathrm{N}$ & Relaxation percentage \\
\hline Esha Seal 2C-I & 20 & 185.1 & 9.7 & 94.76 \\
& 10 & 148.5 & 35.4 & 76.12 \\
& 0 & 319.0 & 182.7 & 42.74 \\
Esha Seal 2C-II & -10 & 301.2 & 231.7 & 23.10 \\
& 20 & 199.3 & 15.3 & 92.34 \\
& 10 & 195.3 & 23.5 & 87.97 \\
& 0 & 293.3 & 127.6 & 56.5 \\
& -10 & 309.2 & 214.9 & 30.5 \\
\hline
\end{tabular}


Fig. 8 Relaxation curves for Esha Seal 2C-I at four different temperatures

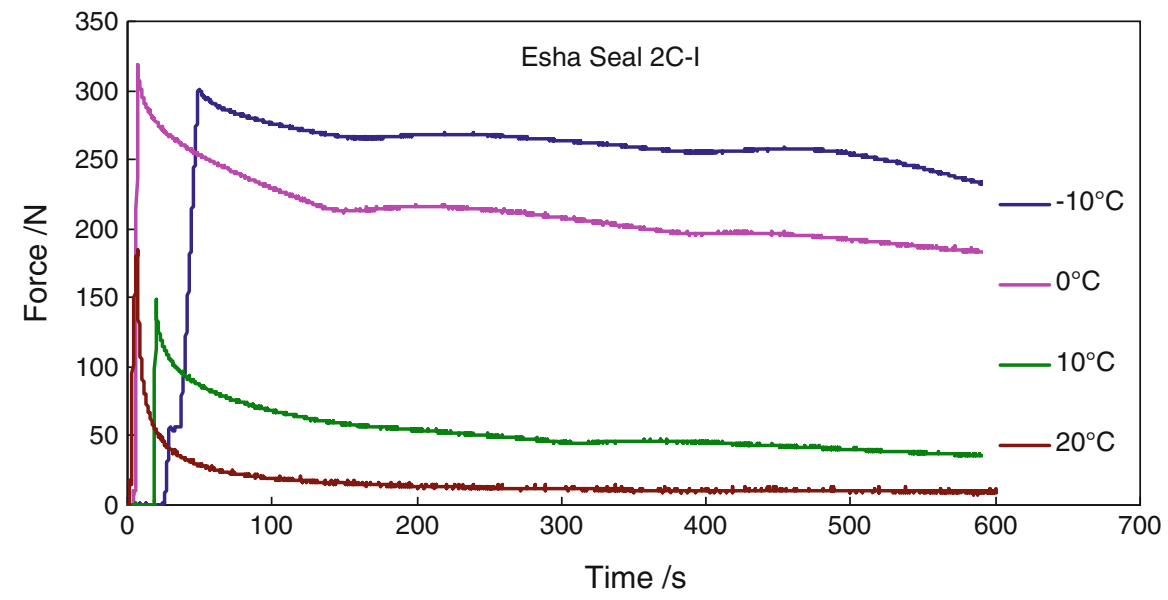

Fig. 9 Relaxation curves for Esha Seal 2C-II at four different temperatures

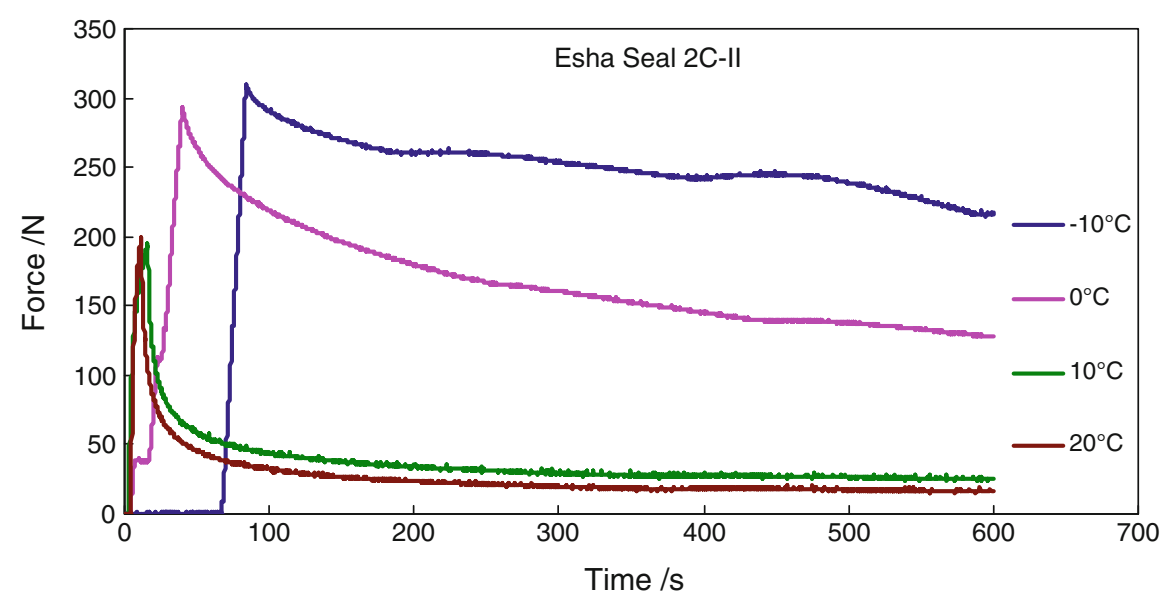

pen grade bitumen was obtained from SK Chemicals, Korea. The physical properties of this bitumen are listed in Table 10 [18].

Figure 12 shows that the two epoxy modified bitumens have higher stiffness values after full curing than the AH90 bitumen. Compared to Esha Seal 2C-I, the larger slope for Esha Seal 2C-II of the complex modulus indicates that it is more temperature susceptible, while the slope for AH90 bitumen is even larger.

The phase angle curve of these two component materials are totally different from that of AH90 with a distinct peak value, which decreased dramatically with increase or decrease of frequency. In contrast to the phase angle curve of $\mathrm{AH} 90$ bitumen, it keeps increasing sharply with decreasing frequency. This means that the binder changed from viscous to elastic state. The phase angle of both types of epoxy bitumen is much lower than that of the AH90 meaning that they are more elastic at higher frequencies (lower temperatures).

At lower frequencies, the phase angle of both 2-component binders is around $5^{\circ}$. This indicates that the epoxy modified bitumen behavior like rubber at low frequency and/or high temperature.

\section{Conclusion}

From the DDT, RT and DSR test results of two component epoxy modified bitumen, the following items can be concluded.

(1) The strength development of two-component epoxy bitumen depends on curing temperature. The tensile strength increases with increasing curing time/temperature and can be described with a sigmoidal curve function. The curing 
Fig. 10 Comparison of complex modulus between Esha Seal 2C-I and 2C-II

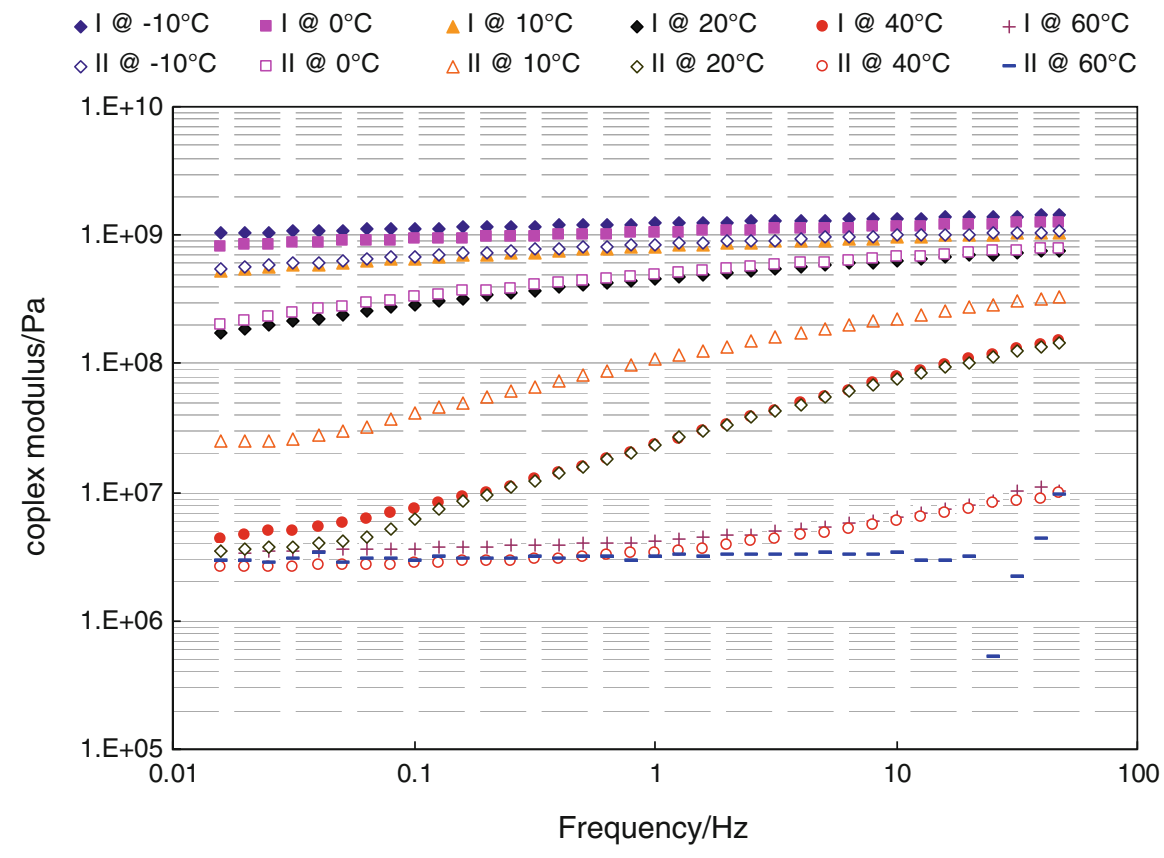

Fig. 11 Comparison of phase angle between Esha Seal 2C-I and 2C-II

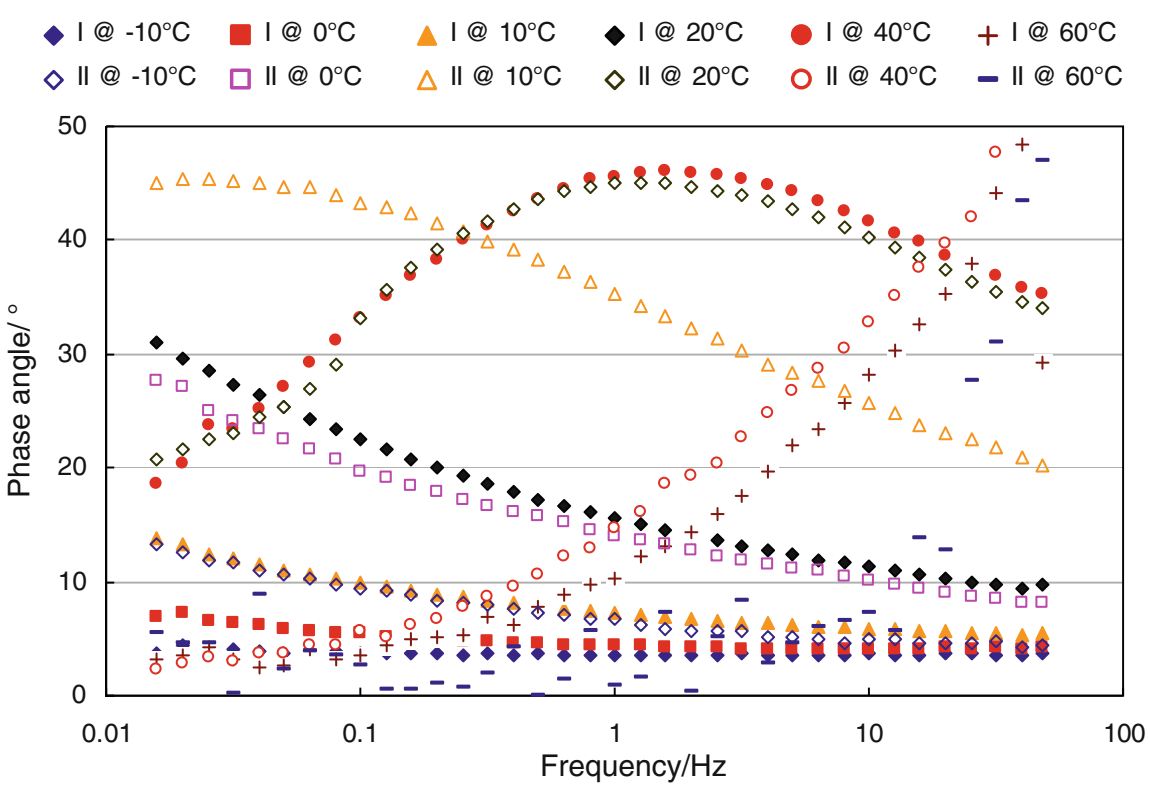

speed can be easily adjusted by changing the additive content.

(2) The tensile strength after full curing is much higher than the tensile strength of bitumen, which implies that runways can be reopened for planes very quickly when epoxy modified bitumens are applied in surface layers.
(3) The tensile strength increases with decreasing test temperature and increasing loading speed. Although at lower temperature $\left(-10^{\circ} \mathrm{C}\right)$, these two binders still have reasonable relaxation behavior. They do neither have high ductility as bitumen binder at higher temperature, nor high brittleness as bitumen binder at lower 
Table 9 Phase angle and complex modulus at $10 \mathrm{~Hz}$

\begin{tabular}{llrlr}
\hline Esha Seal 2C-I & & Temp. $\left({ }^{\circ} \mathrm{C}\right)$ & & \multicolumn{2}{l}{ Esha Seal 2C-II } \\
\cline { 5 - 6 } Phase angle (degree) & Complex modulus $(\mathrm{MPa})$ & & Complex modulus $(\mathrm{MPa})$ & Phase angle $\left({ }^{\circ}\right)$ \\
\hline 3.65 & 1350 & -10 & 991 & 5.00 \\
4.11 & 1160 & 0 & 674 & 10.02 \\
5.89 & 962 & 10 & 225 & 25.78 \\
11.26 & 639 & 20 & 75.5 & 40.31 \\
41.68 & 78.1 & 40 & 5.98 & 32.79 \\
28.16 & 6.47 & 60 & 3.31 & 7.24 \\
\hline
\end{tabular}

Fig. 12 Master curves of complex modulus and phase angle of $2 \mathrm{C}$-I, $2 \mathrm{C}$-II and $\mathrm{AH}$ 90 bitumen

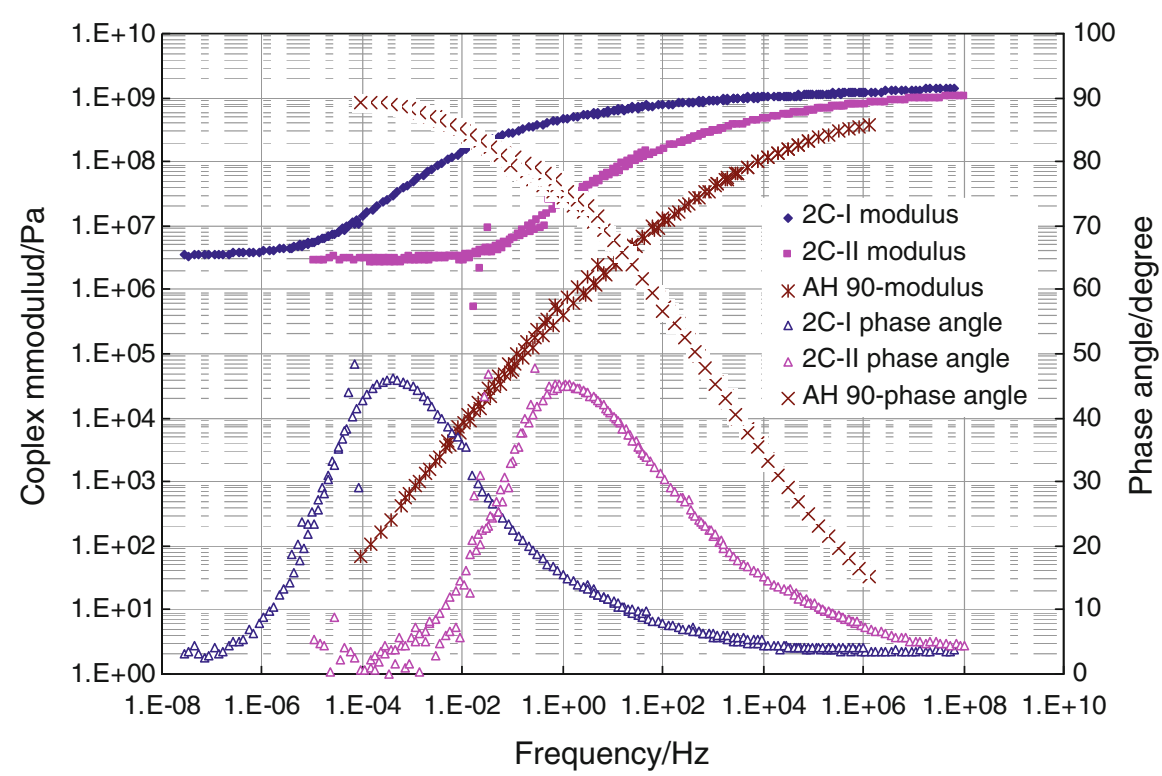

Table 10 Specifications of pen grade bitumen 90

\begin{tabular}{llll}
\hline Indicator & Test method & Specifications & Results \\
\hline Penetration $/ 0.1 \mathrm{~mm}$ & ASTM D5 & $80-100$ & 92.6 \\
Softening point, Minimum $/{ }^{\circ} \mathrm{C}$ & ASTM D36 & $>45$ & 47.8 \\
$60^{\circ} \mathrm{C}$ Viscosity, Minimum $/ \mathrm{Pa} \mathrm{s}$ & ASTM D217 & $>160$ & 187 \\
$15^{\circ} \mathrm{C}$ Ductility, Minimum $/ \mathrm{cm}$ & ASTM D113 & $>100$ & $>150$ \\
\hline
\end{tabular}

temperature. These properties give better resistance to high temperature deformation and better performance at lower temperature.

(4) The complex modulus of both two-component binders is much less susceptible to changes in temperature than that of bitumen. The phase angle of both two-component binders is much lower than bitumen. The results show that both two-component binders have a rubbery behavior at low and/or high temperature.
These conclusions are based on binder tests. In order to get more detailed information about these materials, more properties need to be investigated in the future, such as fatigue resistance, adhesion and water sensitivity. Mixture tests are also required for further research, especially the low temperature behavior.

Acknowledgments The scholarship from the China Scholarship Council is acknowledged. The authors would like to express thanks to ICOPAL BV for their materials and 
technical supports. The test support of J. Qiu and M.F. Woldekidan are also appreciated.

Open Access This article is distributed under the terms of the Creative Commons Attribution Noncommercial License which permits any noncommercial use, distribution, and reproduction in any medium, provided the original author(s) and source are credited.

\section{References}

1. Alabaster D, Herrington P (2008) Epoxy modified opengraded porous asphalt. Road Mater Pavement Des 9(3): 481-498

2. Alabaster D, Herrington PR, Waters JC (2008) Long life open-graded porous asphalt. In: Third international conference on Accelerated Pavement Testing, APT 2008, Madrid, Spain

3. Argue GH (2005) Canadian airfield pavement engineering reference. Ottawa, Canada. http://www.airportsconsult.com/ airfield-pavement/index.html

4. Chen X (2009) On the fracture properties of epoxy asphalt mixture with SCB test. Taylor \& Francis Group, London, ISBN 978-0-415-55854-9, pp 531-540

5. Dubowik DA, Ross GC (2001) A novel waterborne epoxy resin for zero-voc, two component coating. In: 2000 international waterborne high-solids and powder coatings symposium, New Orleans, USA

6. Elliott R (2008) Epoxy asphalt: concept and properties. Workshop of TRA2008, Ljubljana, April 2008

7. Huurman M (2006) Characterisation of the response, cohesive and adhesive properties of mortars for the LOT research program, Delft University of Technology, Delft, November 2006
8. Huurman M (2007) Lifetime optimisation tool, LOT, main report, report 7-07-170-1, Laboratory of Road and Railway Engineering, Delft University of Technology, Delft, December 2007

9. Jahromi SG, Khoda-II A (2009) Effects of nanoclay on rheological properties of bitumen binder. Construct Build Mater 23(8):2894-2904

10. Jian Q, van de Ven MFC, Wu S et al (2009) Investigating the self healing capability of bituminous binders. Road Mater Pavement Des 10/SI:81-94

11. Muraya PM (2007) Permanent Deformation of Asphalt mixtures. PhD thesis, Delft University of Technology. ISBN-13: 978-90-9021895-3

12. Put R (2006) Managing the risks of an international brand name. Master Thesis. University of Twente

13. Qiu J, van de Ven MFC, Wu SP et al (2009) Investigating the self healing capability of bituminous binders. In: Third international asphalt conference, China. Road Mater Pavement Des 10(SI):81-94

14. Rooijen V, De Bondt, Corun (2004) Performance Evaluation of Jet Fuel Resistant Polymer-Modified Asphalt for Airport Pavements. 2004 FAA Worldwide airport transfer conference, USA

15. TRB E-C068 (2004) New Simple Performance Tests for Asphalt Mixes. ISSN 0097-8515, September 2004

16. van de Ven MFC, Medani TO, Molenaar AAA (2004) Open synthetic wearing course. In: 83rd Annual TRB Meeting, Washington DC 2004

17. van Leest AJ, Gaarkeuken G (2005) The F.O.D. resistance of surface layers on airfields in the Netherlands; in situ and laboratory testing. 2004 FAA Airport Technology Transfer Conference, Atlantic City, New Jersey

18. Yu J, Wang L, Zeng X et al (2007) Effect of montmorillonite on properties of styrene-butadiene-styrene copolymer modified bitumen. Polym Eng Sci 47(9):1289-1295 